\title{
Existentiality and Implicatures
}

\author{
Yoon-kyoung $\mathrm{Joh}^{\dagger}$ \\ Mokpo National University
}

\begin{abstract}
This paper claims that an existential reading of bare nouns, used with the progressive form of a stage-level predicate, can be explained by the fact that the temporariness implicature of the progressive is incompatible with genericity. Furthermore, this paper argues that an existential reading of bare nouns employed in the there-be construction should be approached in parallel with the definiteness effect observed with respect to the construction. That is, the referentiality status of the there-be construction evokes a scalar implicature that negates scales stronger than referentiality. Thus, restricted generics are ruled out in the construction. These pragmatic accounts have an apparent advantage, since they can handle exceptions more adequately than any syntactic or semantic analyses.
\end{abstract}

Keywords: existential, generic, progressive, temporariness implicature, scalar implicature

\section{Introduction}

Carlson (1977), Kratzer (1989), and Diesing (1992) note that bare plurals are ambiguous between a generic interpretation and an existential reading when they are used with stage-level predicates. Yet, S-G Lee (2016) observes that the English progressive opts for existentiality, ruling out the generic reading of bare plurals as shown in (1). This phenomenon is claimed to be extended to the there-be construction as shown in (2).

(1) Horses are flying above the river.

a. Some (unknown) horses are flying above the river. (existential)

b. ${ }^{*} A$ species of horse is flying above the river. (generic)

\footnotetext{
* This Research was supported (in part) by Research Funds of Mokpo National University in 2017. This paper was presented at the fall conference of the 21st Century Association of English Language and Literature in 2017.

+ Corresponding author: ykjoh@mokpo.ac.kr
} 
(2) There are horses flying above the river.
a. There are some (unknown) horses flying above the river. (existential)
b. *There is a species of horse flying above the river. (generic)

To explain the data presented above, S-G Lee (2016) takes a syntactic approach, claiming that the existentiality of the English progressive comes from the anchoring operation of an event to the implicit aspectual locative head Loc. However, finding limitations in this syntactic account that attributes existentiality to localizability, this paper will provide alternative implicature-based pragmatic explanations that derive the existentiality by ruling out the generic reading.

This paper is organized as follows. First, section 2 will summarize how S-G Lee (2016) tries to account for the existentiality found in the data shown in (1) and (2) and then discuss limitations. Section 3 will present new analyses for the constructions in (1) and (2). The accounts for the two constructions will not be the same but be fundamentally uniform in the respect that both accounts depend on (scalar) implicatures.

\section{Previous Study}

This section will introduce S-G Lee (2016) who provides a syntactic account for the constructions in (1) and (2) in a unified way. Then, I will discuss some limitations detected in the analysis.

\subsection{S-G Lee (2016)}

S-G Lee (2016) first paraphrases the sentence in (3a) as in (3b) and presents its structure as in (4), claiming that the aspectual locative Loc (AT) in (4) functions to anchor and localize the event derived by the progressive form which is combined with the stage-level predicate smoke. This process of localizing events is claimed to yield an existential closure through which all individuals denoted by bare plurals associated with the events are translated as existential automatically.

(3) a. Doctors are smoking. (simple progressive)

b. Doctors are at smoking. (periphrastic progressive) 
(4)

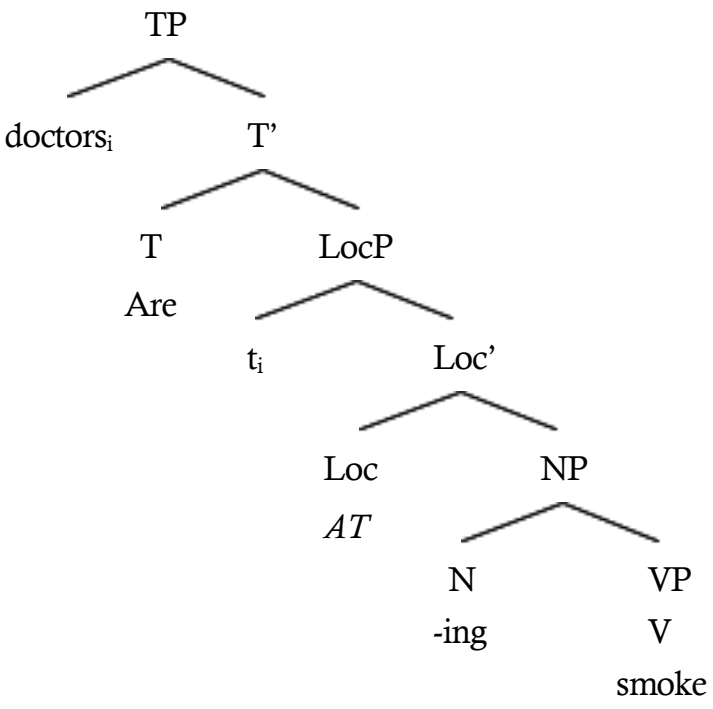

Arguing for the presence of the Locative Phrase (LocP) in the analysis of the progressive construction, S-G Lee (2016) comes up with supporting evidence that is claimed to show us that the English progressive can indeed be analyzed as incorporating aspectual location. First, he cites a couple of studies such as Grady (1967) and Bolinger (1971) who report that the English progressive construction historically originates from a nominalizing morpheme. According to S-G Lee (2016), Bartsch (1986) claims that the current English progressive form - ing was once the form of [be on $V-e n(d)]$. Yet, the unstressed preposition on eventually disappeared and later the present participle - en changed into the form [be V-in(g)]. S-G Lee (2016) further insists that the locative form of the English progressive construction was used even in Modern English, illustrating the following examples. According to him, in Modern English, the sentence in (5a) was able to be paraphrased as the sentence in (5b) with the aspectual locative.

(5) a. He is working

b. He is on working.

Citing Anderson (1973) and Killie (2008), S-G Lee (2016) claims that the fact that the progressive aspect intrinsically involves a locative phrase is cross-linguistically supported as shown in (6). 
(6) a. Der Mann is am/beim Lesen. (German)

the man is at-the reading

'The man is reading.'

b. De man is aan het lezen. (Dutch)

the man is at the reading

'The man is reading.'

S-G Lee (2016) finds additional cross-linguistic evidence: The Korean periphrastic progressive in (7) reveals that the progressive form is rooted in a locative since the predicate consists of three morphemes listed in (8).

(7) [TP pyengsatul-i [VP [LocP [NP [AspP ti [VP tampay-lul soldiersNom cigarette-Accpiwu]-nun]-cwung]-ey] issta]]. (progressive in Korean) smoke-Asp-middle-Loc exist 'Soldiers are in the middle of smoking (a cigarette).' (Lit.)

(8) a. the aspectual morpheme - nun '-ing',

b. the event-denoting nominal - cwung 'middle',

c. the locative - ey 'at/in'.

The last evidence that S-G Lee (2016) presents is from Vlach (1993) who claims that the progressive form in English embraces a locative element, based on the fact that the progressive involves the interpretation of simultaneity when it is used with the when-clause. For instance, the two events in (9) share the interpretation of simultaneity:

(9) a. Kate was working when Bill arrived.

b. Kate was at work when Bill sold the car.

S-G Lee (2016) also tries to analyze the sentence in (10a) under the structure presented in (10b). The essence of the analysis is that the existential marker there co-indexed with the covert aspectual locative head Loc when the sentence projects a stage-level predicate sleeping as a coda phrase and the locative head serves to anchor and localize the event projected by the stage-level predicate sleeping.

(10) a. There are children sleeping in the classroom. 
b.
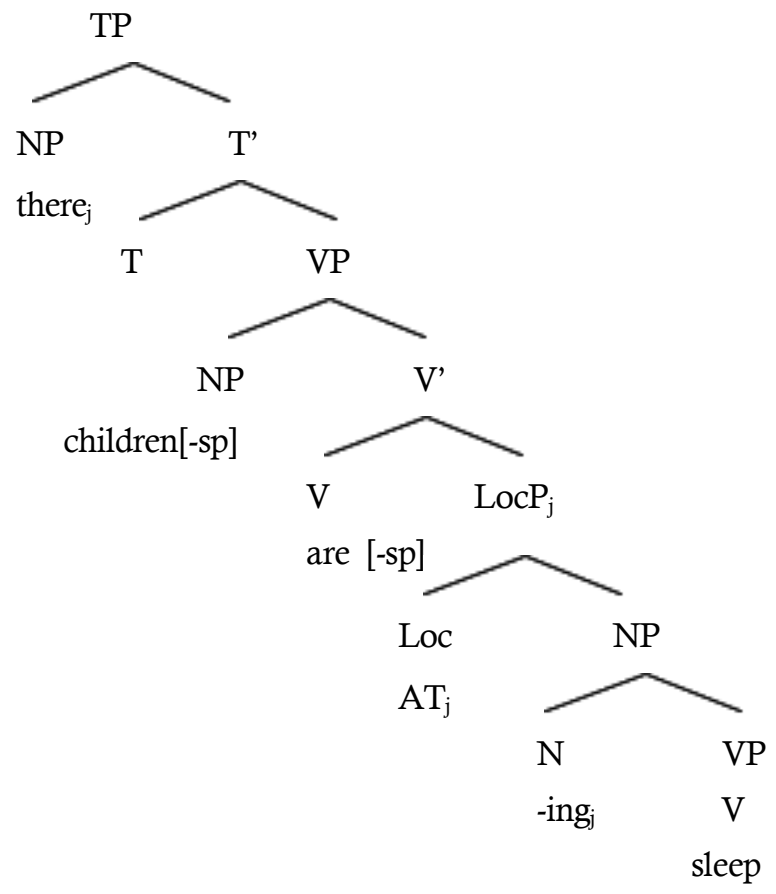

\subsection{Criticisms}

It seems that there is strong evidence for the claim that the progressive can embrace a locative element. However, it is not hundred percent certain how the locative element can produce the existential reading of the progressive. S-G Lee (2016) claims that the event projected by the locative head is existentially closed. It might be a little hasty but it seems that we can get an existential reading whenever there is an event that is existentially closed, according to S-G Lee (2016). However, the operation of existential closure can apply not only to the event denoted by the locative head but also to other events possibly present in the sentence. This might mean that we get an existential reading even without the locative head. Furthermore, as to generating existentiality through existential closure, S-G Lee (2016) seems to follow the approach taken by Diesing (1992). Yet, Diesing's (1992) approach has already been refuted by so-called localists.

Also, the point of the data set presented in (1) and (2) is that the progressive is compatible with the existential reading but rules out the generic reading. Yet, S-G Lee (2016) does not seem to explain the entirety of the phenomena. That is, he tries to explain how the existential reading arrives at when the progressive form is 
employed. However, there is no mechanism to explain why the generic reading is ruled out in the two exceptional constructions. If it is the case that the existential reading derived by an event projected by a locative head automatically rules out the generic reading, the sentence in (11) should not have a generic reading. One possibility that can rescue S-G Lee (2016) is that we assume a mechanism from the Loc analysis that any variables placed out of the anchoring scope of Loc can be generically bound. Yet, this additional assumption can be burdensome.

(11) Dinosaurs were at the point of being extinct.

The sentence in (11) has a locative phrase that can project an event which can eventually be existentially closed. However, the sentence has a generic reading. Thus, explaining how an existential reading can be derived does not necessarily mean that it addresses the issue how the generic reading is ruled out if no additional complications are assumed. Thus, even though we can accept S-G Lee's (2016) way of explaining the existentiality of the progressive, we are still uncertain about how to eliminate the generic reading under his analysis.

Furthermore, as S-G Lee (2016) mentions, Cohen \& Erteschik-Shir (2002), Jager (1995), and Ramchand (1997) claim that the existential there is an explicit realization of a topic event and do not express a location directly. Yet, contrary to their claim, S-G Lee (2016) tries to analyze it as a locative element, even though he claims that the existential there does not directly indicate a spatial location but an aspectual location as an attempt to avoid conflicts with the previous claim. However, the modification does not seem to properly work unless we can make a close connection between an aspectual location and a topic event this time.

Another criticism that I would like to make concerning the there-be construction is that S-G Lee (2016) tries to account for the existentiality of the construction from the locative head that comes with the progressive. This means that the trigger of the existential reading is the progressive form. However, even without the progressive form, the there-be construction can opt for the existential reading, ruling out a generic reading, as shown below. This fact also makes us doubt whether it is truly the locative head of the progressive that is responsible for the existential reading of the construction. Even though the trigger of the existential reading can be identified as the anchoring feature of an event at a specific time, it might be still mysterious how linguistic forms other than the progressive are associated with the locating feature. Thus, to prove the further associations, we need more scrutiny. 
(12) a. There are horses raised by a nun.

b. There are horses in the garden.

The last limitation that I detect regarding S-G Lee's (2016) approach is that it can hardly address any exceptions to the observations made in his study since it provides a rule-like explanation based on strict syntactic structures and semantic operations. However, the reason why this paper would like to suggest an alternative pragmatic approach is that the constructions that we are dealing with seem to allow for exceptions. In section 3.3, I will discuss what kinds of exceptions are possible and how we can properly deal with them.

\section{Proposal}

This section will provide accounts for the two constructions that S-G Lee (2016) deals with. The new analyses in this section will not be as uniform as S-G Lee's (2016). Yet, the underlying mechanism for the two separate analyses will be similar since both of them rely on the concept of implicature.

\subsection{Existentiality of the progressive}

This section will provide an account for the construction in (13) repeated below. The gist of my proposal is that the existential reading arrives at since the generic reading, another option of interpretation, is blocked due to semantic clash.

(13) Horses are flying above the river.

i. Some (unknown) horses are flying above the river. (existential)

ii. *A species of horse is flying above the river. (generic)

To begin with my explanation, I would first like to discuss Zegarac (1993). He proposes that there are three overtones associated with the English progressive such as mild reproof, insincerity and temporariness. Among them, what we would like to focus on is the temporariness sense. Zegarac (1993) describes the semantic contrast between the progressive in (14a) and the simple present in (15a) as the paraphrases in (14b) and (15b). 
(14) a. Kate is living in Philadelphia.

b. An event of Kate's living in Philadelphia obtains at speech time.

(15) a. Kate lives in Philadelphia.

b. The property 'live in Philadelphia' applies to Kate at the time of speech.

The overtone of temporariness or the sense of limited duration is claimed to be derived when the utterance with a progressive form in (14a) is processed in a given context. Especially, Zegarac (1993) relies on the relevance theory to explain it. That is, searching for optimal relevance, the addressee hypothesizes that "John is temporarily an inhabitant of Muswell Hill."

Some researchers like Leech (1971) argue that the temporariness overtone must be the conventionalized linguistic meaning of the progressive. Yet, citing Goldsmith and Woisetschlaeger (1982), Zegarac presents the examples in (16) that show us that there are some circumstances where the temporariness sense is not necessarily felt around even when the progressive form is employed.

(16) a. The Earth is turning on its axis.

b. The Earth turns on its axis.

If the sense of temporariness is truly a conventional meaning of the progressive form, we should not find a case where the temporariness sense is absent at the explicit use of the progressive form. Thus, Zegarac (1993) insists that the set of examples shown in (16) reveals that the temporariness sense of the progressive is an implicature, not a denotation.1) Furthermore, he claims that the implicature of temporariness comes since communication participants seek optimal relevance.

I agree with Zegarac (1993) in the respect that the temporariness sense is an implicature but I find another more convincing account for the temporariness implicature of the progressive. K-S Hong (2013) argues that the temporariness sense of the English progressive is a scalar implicature derived by the Q principle that Horn (1984) suggests.

I will illustrate the Q principle with Kearns's (2000) examples briefly. Since the Q principle dictating "say as much as you can" operates in communication, the hearer assumes that the speaker might have made the strongest statement that can

1) An alternative account might be possible with Chierchia's (1995) Gen or Hab operator that can be placed in the higher position of syntax for the progressive. However, the implicature account seems to be a much simpler approach. 
possibly be uttered. This leads the hearer to negate the stronger form of what the speaker actually said as an implicature. As a result, we get the implicatures in (b) when we utter the sentences in (a) below.

(17) a. It is possible Kate will be elected.

b. Q-implicature: It is not certain that Kate will be elected.

(18) a. Kate is as tall as Bill.

b. Q-implicature: Kate is not taller than Bill.

(19) a. Kate recorded most of the songs.

b. Q-implicature: Kate didn't record all of the songs.

With the Q principle illustrated above, K-S Hong (2013) insists that the temporariness sense of the progressive is a scalar implicature which is derived by the stronger interpretation of the simple tense being negated when the weaker sense of the progressive is employed, generating "it is not the permanent state." This implicature can be drawn since it is assumed that the meaning of the progressive and the meaning of the present constitute a scale where the latter is stronger than the former.

Even though there are two possible pragmatic ways to view the temporariness sense either as an implicature derived by the Relevance principle or as a scalar implicature derived by the $\mathrm{Q}$ principle, we can conclude that it is indeed a type of implicature. Then, the next question is: how does the temporariness implicature generate an existential reading? I would like to claim that the existential reading arrives at since the alternative generic reading is blocked. The reason for the blocking is as follows.

Krifka (1987) makes a claim that generic constructions and habitual constructions share common properties. He also finds that the progressive is incompatible with the habitual sense as shown below. Thus, we can draw the incompatibility between the progressive and the generic construction based upon the similarities between habituatliy and genericity. Yet, I would like to note that this kind of logic can be too common sensical to be considered as a brand-new idea.

(20) a. John smoked. (habitual or non-habitual)

b. John was smoking. (non-habitual only)

Thus, let us move on to Dahl (1973) who claims that the common attribute of 
all generic expressions is that they express nomic, or law-like, statements. From this property, Dahl (1973) claims that they can be used to make predictions as below. Law-like characteristic also implies some degree of extensive duration for genericity. Thus, this nomic property of the genericity seems incompatible with the temporariness sense of the progressive.

(21) My friends vote for reformists. Hence, when you have become my friend, you'll vote for reformists.

Based on the claims above, I would like to explain the reason why the progressive construction rules out the generic reading, leaving behind only the existential reading. The reason is very simple. The nomic character and the habitual property of genericity clash with, or are incompatible with, the temporariness implicature of the progressive since the former expresses a rather stable status that lasts for some extensive duration while the latter conveys the sense of limited stability that is less durable. The semantic clash or incompatibility between them makes the existential reading the only semantic option for the progressive construction. I believe that the account proposed in this section is not only simpler but also more intuitive than S-G Lee's (2016) analysis since native speakers that I consulted with pointed out that it is the temporariness sense that blocks the generic reading in the progressive construction.

\subsection{Existentiality of the There-be construction}

In this section, I would like to account for how the there-be construction repeated in (22) is left only with the existential reading.

(22) There are horses flying above the river.

i. There are some (unknown) horses flying above the river. (existential)

ii. *There is a species of horse flying above the river. (generic)

The gist of my proposal is that the construction in (22) can be explained in the parallel fashion with the examples in the below. The following sentences demonstrate that the English there-be construction reveals the so-called definiteness effect. That is, it cannot be used with strong noun phrases which are definite. ${ }^{2}$ )

2) The definiteness effect has been explained semantically in many studies. However, recently more pragmatic approaches like Zucchi (1995) have been proposed to develop limitations of semantic 
(23) a. There was a cat in the house.

b. There were several cats in the house.

c. There were many cats in the house.

d. There were four cats in the house.

(24) a. \#There was every cat in the house.

b. \#There were most cats in the house.

c. There was Kate in the house.

d. \#There was that cat in the house.

e. \#There was he/him in the house.

To explain the definiteness effect, Y-K Joh (2014) proposes an implicature-based analysis based on the hierarchy in (25) advanced by Gundel et al. (1993) who claim that different referring forms are selected based upon different cognitive statuses that are measured by familiarity. The familiarity scale is also used to explain the choices of many different constructions. In line with this type of accounts, Gundel et al. (1993) analyzes various nominal choices through the giveneness hierarchy.

(25) The Givenness/Familiarity Hierarchy

In focus $>$ activated $>$ familiar $>$ uniquely identifiable $>$ referential $>$ type identifiable

Y-K Joh (2014) claims that the cognitive status of the there-be construction is type identifiability which is placed at the lowest scale of the Givenness Hierarchy. Since the cognitive statuses form a scale, the there-be construction carries the implicature that negates the stronger statuses. Yet, strong NPs that are observed to be illicit in the there-be construction are as strong or stronger than unique identifiability in their cognitive status since it is widely accepted that the distinction between definiteness and indefiniteness is made by the uniqueness scale. Thus, strong NPs cannot be used in the there-be construction since the construction itself carries the implicature that negates the strong NPs' cognitive status.

A new claim that this paper makes is that the definiteness effect observed with respect to the there-be construction is not confined to strong NPs. We can also

theories. The attempt made by Y-K Joh (2014) is one of the pragmatic approaches but I found it somewhat more appealing than others since it directly reflects the fact that the definiteness effect has to do with our cognitive scales of familiarity. 
account for why the there-be construction with bare plurals only opts for the existential reading when it is restricted. To account for this, this paper would like to slightly revise Y-K Joh's (2014) claim. She claims that the cognitive status of the there-be construction is type identifiablility. Yet, it is observed that the construction also licenses referential elements as shown in (26). Gundel et al. (1993) presents the sentence in (26a) to illustrate the referential status and it is observed that the referential element such as indefinite this dog can be used in the there-be construction as shown in (26b). Thus, it is reasonable to raise the cognitive status of the construction from type identifiability to referentiality.

(26) a. I couldn't sleep last night. This cat (next door) kept me awake.

b. I couldn't sleep last night. There is this cat which kept me awake.

Prince (1981) also points out that this-NPs in (27) are licensed in there-be constructions, concluding that they are indefinite, distinguished from the ordinary demonstrative this.

(27) a. A long-hair person doesn't bother me, but when you see that radical with the mop and that shanky garbage and you can smell him a block away, that bothers me. A few years ago, there was this hippie, long-haired, slovenly. He confronted me...

b. One time I went to the roof of this project and there's this big black guy about six seven on top of the stairs. He had his back to me...

c. There was this one checker who was absolutely vicious.

Now, by newly characterizing the cognitive status of the there-be construction as referentiality, we can expect that something type identifiable or referential can be allowed in the there-be construction but any elements as strong or stronger than being uniquely identifiable are ruled out.3) With this in mind, let us turn to the cognitive statuses of relevant NPs. First of all, unrestricted bare plurals which can be either existential or generic are type identifiable and restricted existentials are referential. Thus, they can be allowed in the there-be construction. However, restricted generics

3) I would like to note that only with the revision that shifts the cognitive status of the there-be construction from type identifiability to referentiality, we can explain the existentiality of the there-be construction. However, this modification was not motivated merely to explain new data but is based on a linguistic fact that so-called indefinite demonstratives whose cognitive status is identified as referential can occur in the there-be construction. 
are as strong or stronger than being uniquely identifiable in their cognitive status. Thus, they are incompatible with the construction since the construction carries the implicature that negates the scales stronger than referentiality.

In section 2.2, this paper pointed out that the problem of S-G Lee (2016) is that he cannot explain why the generic reading is impossible in the there-be construction even without the progressive form. We could observe that the existential reading is the only option even when the noun phrases are modified by a past participle or a prepositional phrase, not by a progressive. It is apparent that it is not the progressive itself that operates to derive the existential reading in the there-be construction. Thus, this paper addresses the fact that it is not the progressive form itself but the general restriction imposed on the generic NP that makes the existenetial reading the only possible reading. In other words, when generic NPs get restricted, their cognitive status climbs up high enough to be blocked by the scalar implicature associated with the there-be construction.

\subsection{Advantages}

There are two advantages of my accounts. The first advantage of my analyses based on implicatures can be found in the fact that the constructions that we are dealing with allow for exceptions, as pointed out earlier. According to two Canadian and one American informants, there are special circumstances where the constructions at issue in this paper allow for genericity. For instance, in situations described in (a) below, the sentences in (b) can be uttered. (28b) is the progressive construction and $(29 b)$ is the there-be construction. Under the contexts described in (a), it was observed that the sentences in (b) can be interpreted with a generic reading.

(28) a. In a science class, a teacher explains that all the planets revolve. Then, a student says.

b. It is very interesting that planets are indeed revolving.

(29) a. In a situation, a teacher asks students whether they know of a species that have become extinct. Then, a student utters the following sentence.

b. There were dinosaurs becoming extinct.

However, it must be noted that not all the informants I consulted with agreed with the judgment of the sentences above. One Canadian informant tried to correct 
the (b) sentences above into the following sentences with non-progressive forms. Thus, it seems to be the case that the generic reading in the constructions above is certainly not the most natural one but can somehow be a reading enforced by the given context,4) and we concern the matter of acceptability rather than grammaticality with the examples in (28-30).

(30) a. Dinosaurs became/have become extinct.

b. It is very interesting that planets revolve.

Even though it might be the case that the generic reading in the constructions at issue in this paper is possible only under special circumstances that directly contradict the temporariness sense of the progressive, we should find a way to address them, if they are indeed plausible. To do so, we would like to resort to the very nature of implicatures.

Developing Grice (1975), Blome-Tillmann (2008) puts forth cancellability as tests for implicatures. According to him, there are two kinds of cancellability principles: the principle of explicit cancellability as stated in (31a) and the principle of contextual cancellability as defined in (31b). Blome-Tillmann (2008) claims that both of them can provide us with an effective tool to test whether a certain sense is an implicature or not.

(31) a. If an utterance of $P$ conversationally implicates $q$ in $C$, then utterances of "P, but not Q" or "P, but I don't mean to imply that Q" are admissible in $\mathrm{C}$ and they cancel the speaker's commitment to $\mathrm{q}$.

b. If an utterance of $P$ conversationally implicates $q$ in $C$, then there is a context in which utterances of $\mathrm{P}$ do not commit the speaker to $\mathrm{q}$.

I believe that the cancellability nature of implicatures, especially the principle of contextual canceallbility, can explain the exceptional generic reading of the progressive and of the there-be constructions. The temporariness implicature of the progressive and the scalar implicature derived by the there-be construction ordinarily function to block the generic reading. However, under special contexts that contradict

4) The variations in native speakers' judgments might come from different degrees of background knowledge they have since the cancellation of implicatures is very much affected by our background knowledge. Also, I would like to note that it is commonly observed that native speakers try to revise sentences if they are not the most natural forms that they would usually use. Thus, the native speaker's corrections do not necessarily mean that they are unacceptable. 
the implicatures, they can be cancelled, resulting in apparent exceptions.

Another advantage of my analysis can be found with respect to the data in (32). S-G Lee (2016) discusses the contrast in (32) as problematic in his analysis and tries to explain them with an additional stipulation.

(32) a. There are *some of the horses flying above the river.

b. Some of the horses are flying above the river.

The data in (32) reveal that only a noun phrase whose reference is non-specific can be used as postcopular NP in the there-be construction. That is, the noun phrase some of the horses in (32a) is interpreted to express a specific referent and thus it is blocked as shown. Yet, the specificity effect is not observed in the English progressive construction, as shown in (32b). This seems puzzling since both constructions are supposed to force the associate NP to have an existential reading under S-G Lee's account.

To explain this puzzle, S-G Lee (2016) assumes two different types of the copular verb be. That is, the copular verb be in the there-be sentence comes with the semantic feature of [-specific] which makes the associate NP get its feature checked out. Yet, the associate NP some of the unicorns with the feature [+specific] cannot meet the requirement derived by the copular verb be. This leads the whole derivational process to clash. In contrast to this, there is no semantic feature concerning specificity that is available to the verb $b e$ in the progressive. This results in allowing both specific and non-specific elements to occur as subjects in the progressive.

As discussed above, S-G Lee (2016) had to introduce different feature requirements for the seemingly identical verb be to account for the contrast shown in (32), making the grammar more complex which is already heavy. However, the analyses of this paper can naturally explain the contrast without making any additional claims. The sentence in (32a) is unacceptable since the specific associate NP is stronger than referentiality in its cognitive status and thus it is blocked via a scalar implicature carried by the there-be construction. Yet, the same NP in (32b) is compatible with the temporariness implicature of the progressive and thus the sentence has no reason to be blocked as unacceptable. That is, when we analyze the existentiality of the there-be construction under the same view of dealing with the definiteness effect, the contrast shown in (32) is no longer surprising. The scalar implicature involved in (32a) filters out an element that is more definite than referentiality while the temparoriness implicature associated with (32b) is not affected by the definiteness 
of the nominal element in the same sentence.

\section{Conclusion}

This paper has provided new pragmatic accounts for the constructions that S-G Lee (2016) tries to explain with a syntactic approach. S-G Lee (2016) claims that the existential reading of bare nouns used with the progressive and employed in the there-be construction is derived by the locative structure whose event is existentially closed. Yet, finding many limitations of this account, this paper has presented alternative accounts based on pragmatic implicatures. The essence of my claim is that the existential reading comes about since another interpretation of genericity is blocked due to the temporariness implicature of the progressive and the scalar implicature of the there-be construction. There are two apparent advantages in my accounts. My proposal can address some exceptional cases which a strict syntactic account cannot properly handle. Also, my proposal does not have to make any stipulations about the specificity of the verb when a contrast is observed with respect to the possible types of noun phrases that can occur in the constructions.

\section{References}

Anderson, John. (1973). An Essay Concerning Aspect. The Hague: Mouton.

Bartsch, Renate. (1985). On aspectual properties of Dutch and German nominalizations. In

Vincenzo Lo Cascio and Co Vet, ed., Temproal Structure in Sentence and Discourse, 7-39.

Dordrecht: Foris Publications.

Blome-Tillmann, Michael. (2008). Conversational implicature and the cancellability test. Analysis 68, 156-160.

Bolinger, Dwight. (1971). The nominal In the progressives. Linguistic Inquiry 2, 246-250.

Carlson, Gregory. (1977). A unified analysis of the English bare plural. Linguistics and Philosophy 1, 413-457.

Cohen, Ariel and Nomi. Erteschik-Shir. (2002). Topic, focus, and the interpretation of bare plurals. Natural Language Semantics 10, 125-165.

Dahl, östen. (1973). On generics. In Edward Keenan, ed., Formal Semantics of Natural Language, 99-112. London \& New York: CUP.

Diesing, Molly. (1992). Bare plural subjects and the derivation of logical representation. Linguistic Inquiry 23, 353-380. 
Goldsmith, John. and Erich. Woisetschlaeger. (1982). The logic of the English progressive. Linguistic Inquiry 13, 79-89.

Grady, Michael. (1967). On the essential nominalizing function of English -ing. Linguistics 34, 5-11.

Grice, Paul. (1975). Logic and conversation. In Peter Cole and Jerry Morgan, ed., Syntax and Semantics Vol. 3: Speech Acts, 43-58. New York: Academic Press.

Gundel, Jeanette, Nancy. Herdberg and Zacharski, Ron. 1993. Cognitive status and the form of referring expressions in discourse. Language 69, 274-307.

Hong, Ki-Sun. (2013). The progressive in English and Korean. Korean Journal of Linguistics 38, 1049-1092.

Horn, Lawrence. (1984). Toward a new taxonomy for pragmatic inference: Q-based and R-based implicature. In David Schiffrin, ed., Meaning, Form and Use in Context, 11-42. Washington: Georgetown University Press.

Jager, Gerhard. (1995). The stage/individual contrast revisited. WCCFL 15, 225-240.

Joh, Yoon-kyoung. (2014). The definiteness effect as a scalar implicature. English Language and Literature 21 27, 189-207.

Kearns, Kate. (2000). Semantics. New York: St. Martin's Press.

Killie, Kristin. (2008). From locative to durative to focalized: The progressive and PROG imperfective drift. In Maurizio Gotti, Marina Dossena, and Rury Richard, ed., English Historical Linguistics 2006: Syntax and Morphology, 69-88. Amsterdam: John Benjamins.

Kratzer, Angelika. (1989). Stage-level and Individual-level Predicates. Ms., Amherst: University of Massachusetts.

Krifka, Manfred. (1987). An Outline of Genericity. Ms., Universität Tübingen.

Lee, Sang-Geun. (2016). A locative approach to the existentiality of the English progressives. English Language and Linguistics 22, 133-148.

Prince, E. (1981). On the inferencing of indefinite-this NPs. In Aravind Joshi, Bonnie Webber, and Ivan Sag, eds., Elements of Discourse Understanding, 231-250. Cambridge: Cambridge University Press.

Ramchand, Gillian. (1997). Aspect and Predication: The Semantics of Argument Structure. Oxford: Clarendon Press.

Vlach, Frank. (1993). Temporal adverbials, tenses and the perfect. Linguistics and Philosophy 16, 231-283.

Zegarac Vladimir. (1989). Relevance theory and the meaning of the English progressive. UCL Working Papers in Linguistics 1, 19-32.

Zucchi, A. (1995). The ingredients of definiteness and the definiteness effect. Natural Language Semantics 3, 33-78. 
Yoon-kyoung Joh

Mokpo National University

1666 Yeongsan-ro, Muan-gun, Jeonnam 58554, Korea

E-mail: ykjoh@mokpo.ac.kr

Received: October 23, 2017

Revised version received: December 19, 2017

Accepted: December 28, 2017 